\title{
História (do Tempo Presente), memória e trauma na Ditadura do Estado Novo no Brasil (1937-1945)
}

Wagner Augusto Hundertmarck Pompéo ${ }^{I}$

Resumo: Por se tratar de um período de bastante violência, ameaça e repressão, a Ditadura do Estado-Novo de Vargas vem chamando cada vez mais a atenção de historiadores que, atentos a relação entre história (do tempo presente), memória e trauma, voltavam-se mais comumente ao Golpe de 1964 para justificar a necessidade de construção do que se pode chamar de uma memória coletiva. Partindo desse contexto, o presente trabalho, para além de explorar as relações entre história (do tempo presente), memória e trauma, procurará melhor compreender a Ditadura do Estado-Novo, que perdurou de 1937 a 1945, bem como porquê, diante de episódios tão importantes e representativos como esse, nos foi imposto, no mais das vezes, um dever de silêncio e esquecimento. Adotando metodologia bibliográfica e método dedutivo, o trabalho conclui, ao seu final, que, em paralelo ao trauma que atinge as vítimas, é o Estado um dos que mais contribui para um esquecimento desses episódios que, pelo contrário, merecem ser lembrados e sobretudo discutidos criticamente, como forma de disso retirarmos valiosas contribuições para nos afastar desse mesmo passado em direção a um futuro diferente.

Palavras-chave: História, memória, trauma, ditadura e Brasil.

\section{History (of Present Time), memory and trauma in the dictatorship of the New State on Brazil (1937-1945)}

Abstract: Because it is a period of considerable violence, threat and repression, the dictatorship of the new state of Vargas has increasingly called attention to historians who, attentive to the relationship between history (of present time), memory and trauma, were more commonly returned to Coup de 1964 to justify the need for construction of what can be called a collective memory. Starting from this context, the present work, in addition to exploring the relationships between history (of the present time), memory, trauma, will seek better understanding the dictatorship of the new state, which has pursued from 1937 to 1945, as well as why, faced with such important episodes and Representative such as this, it has been imposed on us, at most times, a duty of silence and oblivion as to episodes like this. Adopting bibliographical methodology and deductive method, the work concludes, at its end, that, in parallel to the trauma that reaches the victims, it is the state one of the most contributing to an oblivion of these episodes which, on the contrary, deserve to be remembered and, above all, discussed Critically, as a way of this, we withdraw valuable contributions to keep us from the same past towards a different future.

Keywords: History, memory, trauma, dictatorship and Brazil.

Artigo recebido em 15/08/2018 e aprovado em 20/11/2018. 


\section{HISTÓRIA (DO TEMPO PRESENTE), MEMÓRIA E TRAUMA NA DITADURA DO ESTADO NOVO NO BRASIL (1937-1945) \\ WAGNER AUGUSTO HUNDERTMARCK POMPÉO}

\section{INTRODUÇÃO}

No ano em que a Ditadura do Estado-Novo de Vargas completa 80 anos, muitos são os trabalhos que adotam esse período histórico como objeto de estudo, marcadamente no que diz respeito a (re)construção da história social do trabalho, afinal é nessa época que se observou a sistematização da legislação trabalhista, a fixação do valor do salário mínimo, a decretação da Consolidação das Leis do Trabalho (CLT), entre outros.

Situada em meio a um conflito que envolve, por um lado, um discurso de doação e proteção da classe trabalhadora por Vargas, e, de outro, uma noção de que tal discurso não se sustenta, maquiando falsamente a temática, uma vez que a positivação de direitos teria sido resultado direto dos episódios de luta da classe trabalhadora por reconhecimento, temos por incontroverso que, embora não da mesma forma como ocorreria a partir de 1964, o golpe de 1937 também foi um período ditatorial que deixou marcas profundas em suas vítimas.

À essa razão, embora a historiografia já tenha despertado para a relação existente entre história (do tempo presente), memória e trauma na experiência ditatorial no Brasil a partir de 1964, ainda são pouco representativos os estudos envolvendo, em especial, a ditadura do Estado-Novo de Vargas, por mais que se saiba que, tanto quanto naquela, nesta existiu, sim, muitos episódios de ameaça, violência e repressão.

Partindo desse contexto, para além de explorar as relações entre os conceitos acima mencionados - história (do tempo presente), memória, trauma -, o presente trabalho objetivará também melhor compreender a ditadura do Estado-Novo (19371945), questionando o porquê de, diante de episódios tão importantes e representativos como esse, nos foi imposto, durante muito tempo, um dever de silêncio e esquecimento quanto as arbitrariedades havidas ao longo desse período.

Para tanto, o trabalho será dividido em três partes. Na primeira, procurar-se-á, em meio a contextualização do Estado-Novo, relatar alguns dos principais eventos envolvendo ameaça, violência e repressão. Feito isso, a segunda parte se encarregará da relação entre história (do tempo presente) e as novas perspectivas trazidas pelas Lei de acesso a informação pública, aprovada, sancionada e publicada em 2011. No terceiro e último tópico, abordar-se-á memória, esquecimento, trauma, luto e melancolia, enquanto conceitos fundamentais a possibilidade que temos de escrever a história a partir de uma perspectiva traumática. Por fim, em sede conclusiva é a vez de analisarmos os fatores que se acredita impuseram, durante muito tempo, o silêncio e esquecimento que, infelizmente, freiam que acontecimentos tão sensíveis e representativos como esse deixem de ser problematizados e discutidos criticamente.

Adotando metodologia bibliográfica e método dedutivo, o trabalho conclui, ao seu final, que, em paralelo ao trauma que atinge as vítimas, é o Estado um dos que mais contribui para um esquecimento desses episódios que, pelo contrário, merecem ser lembrados e, sobretudo, discutidos criticamente. 


\title{
1. ESTADO-NOVO: AMEAÇA, VIOLÊNCIA E REPRESSÃO
}

Fruto do chamado Plano Cohen, que, como dito por Boris Fausto, trata-se de obra de ficção e que tem até hoje muitos aspectos obscuros, o movimento de trinta se deu depois que o oficial integralista capitão Olímpio Mourão Filho "foi surpreendido, ou deixou-se surpreender, em setembro de 1937, datilografando no Ministério da Guerra um plano de insurreição comunista" de imediato "passado das mãos dos integralistas à cúpula do Exército"II .

Como efeitos de sua divulgação, por maioria de votos, reunido, o Congresso teve por bem aprovar de maneira expressa não só a suspensão de garantias constitucionais por noventa dias, como, principalmente, o próprio estado de guerra.

Concomitantemente a isso, Getúlio trouxe a público o início de uma nova fase política e a entrada em vigor de uma nova carta constitucional, a qual, de estilo autoritário, exatamente como havia sido encomendado a seu elaborador, Francisco Campos, o presidente ficava autorizado a governar via decretos-leis, deixando de lado a realização de plebiscitos e mesmo eleições para o parlamento ${ }^{\mathrm{III}}$.

Não é à toa, portanto, que ao longo desse período o Brasil avançou em direitos sociais, ao passo em que, em se tratando de direitos políticos, obteve conquistas mínimas, e, além disso, como dito por Carvalho ${ }^{\text {IV }}$, viveu limitações ou esteve sujeito a vários recuos ${ }^{\mathrm{V}}$, já que vigilância, repressão e a criminalização dos movimentos políticos e sociais se proliferaram de maneira intensa, fruto do que se pode chamar de uma polícia política.

Nesse aspecto, como bem lembrando por Diorge Alceno Konrad:

\begin{abstract}
"Mesmo que consideremos que toda ação policial seja uma ação política, a definição institucional da polícia política só se dará no Brasil na década de 1930. A partir daí, o país possuirá uma polícia cada vez mais a serviço do poder político, através de uma instituição especializada do Estado, como um poder organizado para a opressão de classe. Além disso, tornar-se-á uma das principais armas do poder para a vigilância e a repressão aos movimentos sócios políticos do período, colaborando, principalmente pelo medo, na criação de uma atmosfera de maior apoio aos governantes. A partir daí, para os integrantes da polícia política, muitas vezes, a simples intenção era motivo para enquadrar alguém como 'criminoso', pois essa instituição passava a ter funções e poderes acima das leis, em moldes idênticos aos da Gestapo, na Alemanha nazista",VI.
\end{abstract}

No caso do Estado-Novo, no entanto, em paralelo ao uso da força física, a autoridade do estado também se deu mediante práticas de violência simbólica. A esse respeito, "chamamos de violência simbólica a iniciativa do Estado em estabelecer uma dominação ideológica, cultural e comportamental da sociedade"VII , a qual, ao longo do referido período justamente constituiu-se na razão de ser do Departamento de Imprensa e Propaganda (DIP) instituído por Vargas e cujas atribuições, não por acaso, cingia-se a:

\footnotetext{
“(...) centralizar, coordenar, orientar e superintender a propaganda nacional, interna ou externa (...) fazer a censura do teatro, do cinema, funções recreativas e esportivas (...) da radiodifusão, da literatura (...) e da imprensa(...) promover, organizar, patrocinar ou auxiliar manifestações cívicas ou exposições demonstrativas das atividades do Governo" VIII.
}

Não obstante, a violência esteve institucionalizada antes mesmo do golpe do 


\section{HISTÓRIA (DO TEMPO PRESENTE), MEMÓRIA E TRAUMA NA DITADURA DO ESTADO NOVO NO BRASIL (1937-1945) \\ WAGNER AUGUSTO HUNDERTMARCK POMPÉO}

Estado-Novo, afinal, entre 1930 a 1937 "raros foram os momentos em que a polícia não agiu através da vigilância, da espionagem, da violência e da repressão no tratamento de questões políticas e sociais" $"$.

Prova disso é que segundo Fernanda Torres Magalhães, "buscas e apreensões nas residências ou locais de trabalho dos vigiados constituíam-se em práticas constantes da rotina policial", em exercício de um "ato legitimado pelos dados obtidos através da vigilância e pelo próprio poder que a sociedade conferia a tais órgãos". Tanto que, a partir de prontuários da Delegacia da Ordem Política e Social de São Paulo (DEOPS), descobriram-se muitas cartas enviadas por populares delatando outros populares, em tese suspeitos ${ }^{\mathrm{X}}$.

É por esse cenário que nos parece necessário, para além do golpe militar de 1964, fazer uma relação entre história, memória e trauma também que no toca a esse importante período histórico, seja pela institucionalização da violência física, seja pelo seu viés simbólico, que, no mais das vezes, revela-se ainda mais difícil de ser apagado do psicológico das vítimas.

\section{HISTÓRIA (DO TEMPO PRESENTE) E DITADURA: NOVAS PERSPECTIVAS A PARTIR DA LEI 12.527/2011}

Depois de um longo processo de lutas contra o excesso de sigilo, iniciado ainda antes do final da ditadura militar, quando imposto pela própria atuação governamental, a aprovação da Lei $n^{\circ}$ 12.527/2011, popularmente conhecida como "lei de acesso à informação pública", marca o início de um novo tempo, caracterizado por uma conquista que importa não apenas a historiadores, como, sobretudo, aos cidadãos em geral, consistente na chamada "abertura" de seus "arquivos secretos" e da instituição da "Comissão Nacional da Verdade"XI.

Esse fato, para além de permitir a (re) construção de importante parte da história nacional tradicional, acaba se revelando de fundamental importância a necessidade que temos de, a partir do presente ${ }^{\mathrm{XII}}$, pensar a ditadura militar brasileira em um contexto mais abrangente ou, em outras palavras, em conjunto com outros "eventos traumáticos" ocorridos ao longo do século XX ${ }^{\mathrm{XIII}-\mathrm{XIV}}$.

Desse modo, não se tem dúvidas de que essa forma de problematização de acontecimentos históricos que se relacionam entre si apesar de ocorridos em locais e com características diversas um do outro, é importantíssimo para que se possa buscar entender como a escrita da história, "aliada ao trabalho de memória, pode ocupar lugar importante a partir do qual é possível dar sentido às experiências traumáticas do passado e cujas ressonâncias encontram-se ainda no presente" $\mathrm{XV}$.

Serve, portanto, não somente para melhor elaborar acontecimentos passados, como, principalmente, consolidar de maneira mais efetiva a chamada história do tempo presente. A esse respeito, aliás, muito embora como lembrado Carlos Fico "ainda hoje persiste alguma suspeita contra a história que não tem um bom recuo temporal", na medida em que isso impossibilitaria uma análise imparcial dos fenômenos, não se pode esquecer que "muitas vezes se confunde recuo temporal e perspectiva (no sentido de ângulo ou ponto de vista)", afinal "o recuo temporal não conduz necessariamente a uma análise isenta de perspectiva, já que se pode analisar um objeto muito recuado no tempo a partir de diversos enfoques"XVI. 


\title{
HISTÓRIA (DO TEMPO PRESENTE), MEMÓRIA E TRAUMA NA DITADURA DO ESTADO NOVO NO BRASIL (1937-1945)
}

WAGNER AUGUSTO HUNDERTMARCK POMPÉO

É entremeio a esse debate de fundo teórico-metodológico que, tendo sujeito e objeto imersos em uma mesma temporalidade, estudos mais recentes tem procurado ir além da mera relação entre memória, trauma e ditadura, para alcançar, principalmente, também o luto e a melancolia característicos de episódios como esse.

\section{MEMÓRIA, ESQUECIMENTO, TRAUMA, LUTO E MELANCOLIA:}

"Quais modos de compreensão desse passado e de seu processamento podem contribuir para nos afastar desse mesmo passado em direção a um futuro diferente?" foi a pergunta que Jörn Rüsen utilizou para sintetizar, de maneira bastante feliz, ainda no prologo do artigo intitulado "Como dar sentido ao passado: questões relevantes de meta-história"XVII o ponto de partida da reflexão que propõe a respeito do verdadeiro papel da memória sob e perspectiva do trauma.

Jörn Rüsen não é o único a refletir quanto ao assunto, no entanto. O tema tem atraído inúmeros historiadores, afinal de contas, como aponta Jay Winter, vivemos um "boom de memória", já que:

\begin{abstract}
"Por toda a Europa tem ocorrido um debate multifacetado e prolongado sobre como comemorar o Holocausto. Esses projetos têm sido um ímã para controvérsias e disputas, mas independentemente do que se pense sobre a possibilidade ou desejabilidade de 're-apresentar' o Holocausto, o próprio tema faz muitas pessoas, tanto na Europa como além dela, refletir sobre a noção de memória e sobre que tipos de memórias são desencadeadas por outros projetos comemorativos"XVIII.
\end{abstract}

É por isso que, segundo o autor, as propostas de construção de memórias coletivas precisam ser vistas com bastante atenção e cuidado, afinal "agentes do governo tanto quanto aqueles dedicados à constituição de um Estado têm um interesse evidente em legitimar narrativas", sobretudo pelo contexto da "geração da memória" XIX em que vivemos

Isso quando não a intenção, ao invés de legitimar narrativas, é impor um dever de esquecimento, a exemplo do ocorrido no caso brasileiro da ditadura militar, instituída a partir do golpe de primeiro de abril de 1964, e sua consequente Lei de Anistia, que visava, nas palavras de Glenda Mezarobba, uma "conciliação pragmática"xx , já que proposta de maneira ampla, geral e irrestrita.

Conciliação essa que se caracteriza pela postura que teve o Estado brasileiro, que muito mais do que ter procurado dar conta das penas e crimes comuns, teve por bem tratar, em mesma medida, dos crimes políticos. Preocupou-se, em outras palavras, com a pacificação dos espíritos, cujo objetivo fundamental era extinguir duplamente as consequências sofridas, fosse por torturados, fosse por torturadores.

Desse modo, justo nos parece haja uma melhor exploração de tema ligados a memória, esquecimento, trauma, bem como luto e melancolia, no que toca as experiências ditatoriais havidas no Brasil. Isso porque, apesar de bastante sensível, somente a partir desse imbricamento é que será possível alcançar a proposta de "memória coletiva"XXI mencionada por Maurice Halbwachs, uma vez que:

“(...) la memoria colectiva es el proceso social de reconstrucción del pasado vivido y experimentado por un determinado grupo, comunidad o sociedad. Este pasado vivido es distinto de La historia, La cual se refiere más bien ala serie de fechas y eventos registrados, como dados e como hechos 


\section{HISTÓRIA (DO TEMPO PRESENTE), MEMÓRIA E TRAUMA NA DITADURA DO ESTADO} NOVO NO BRASIL (1937-1945)

WAGNER AUGUSTO HUNDERTMARCK POMPÉO

independientemente de si éstos han sido sentidos y experimentados por alguien"XXII.

Se antes já se falava da essencialidade do(s) depoimento(s) enquanto ferramenta à historicização da memória, a partir de 2011 esse coro ganhou ainda mais força, já que com a sanção, promulgação e publicação da Lei de Acesso a informação pública - que como antes mencionado, além de proceder a "abertura" dos "arquivos secretos" da ditadura passou a também instituir as "Comissões da Verdade" -, reforçouse a importância que tem esses relatos.

Até porque, como aponta Maurice Halbwachs, existe uma intrínseca relação entre a memória individual e a memória coletiva. Embora passa parecer algo particular, a memória remete a um grupo, já que por mais que carregue em si a lembrança, o indivíduo sempre está em constante interação na sociedade. Em suas palavras, "nossas lembranças permanecem coletivas e nos são lembradas por outros, ainda que se trate de eventos em que somente nós estivemos envolvidos e objetos que somente nós vimos"XXIII.

Porém, não se pode esquecer que:

\footnotetext{
“(...) para que a nossa memória se aproveite da memória dos outros, não basta que estes nos apresentem seus testemunhos: também é preciso que ela não tenha deixado de concordar com as memórias deles e que existam muitos pontos de contato entre uma e outras para que a lembrança que nos fazem recordar venha a ser constituída sobre uma base comum"XXIV .
}

A memória individual não deixa de existir, portanto. Pelo contrário, enraizada em diferentes contextos e presente em distintos participantes, ela mantém sua natureza pessoal quanto ao um conjunto de acontecimentos que, partilhados por um grupo, faz com que passe de uma memória individual para uma memória coletiva ${ }^{\mathrm{XV}}$.

Assim, se "o trauma é caracterizado por seu uma memória de um passado que não passa", ou, em outras palavras, como uma ferida que não cicatriza, mostrando-se como "fato psicanalítico prototípico no que concerne à sua estrutura temporal" ${ }^{\mathrm{XXVI}}$, não se tem dúvidas de que a história precisa da narrativa das vítimas da ditadura e outros eventos traumáticos para incorporar sua dimensão traumática.

Para que isso ocorra, porém, é imprescindível o trabalho de luto, que segundo a interpretação que se faz de Freud, a partir dos textos "Luto e melancolia"XXVII e "Recordar, repetir e elaborar", consiste em reconhecer e assimilar dada perda afetiva, propiciando-se possa a vida continuar em seu ritmo normal ${ }^{\mathrm{XXVIII}}$. Mesmo que o trabalho de luto se realize, as perdas e traumas não são apagados da memória, fato que ocorre também quando se nota o melancólico, experienciado quando não se consegue inserir o objeto perdido no curso da vida.

Segundo Walkiria Oliveira Santos, "no plano coletivo, o trabalho de luto e a melancolia são dimensões importantes das sociedades que, tais como os indivíduos, atravessam períodos traumáticos que precisam ser realocados no curso da vida social". Por isso, complementa, "os traumas coletivos necessitam igualmente serem representados no plano simbólico, na memória coletiva, contribuindo assim para a continuidade da vida normal das sociedades" XXIX .

Em obra intitulada "A memória, história e esquecimento", Paul Ricoeur aponta para a rememoração como forma de viabilizar que o trabalho de luto seja realizado, afinal de contas, assim não o fazendo, as "feridas simbólicas que pedem uma cura", 


\section{HISTÓRIA (DO TEMPO PRESENTE), MEMÓRIA E TRAUMA NA DITADURA DO ESTADO}

NOVO NO BRASIL (1937-1945)

WAGNER AUGUSTO HUNDERTMARCK POMPÉO

posto constituem uma "memória ferida" ou "memória impedida", tendem a reaparecer, adquirindo a forma de uma repetida compulsão melancólica $\mathrm{xxx}$.

Por isso, não é à toa, Dominick LaCapra diz que quem se dedica a estudar a escrita da história sob a perspectiva do trauma deve ser movido por um "desassossego empático" XXXI, já que, segundo Maria Rita Kehl, se a tortura resistiu tanto tempo como sintoma social é por nossa "displicência histórica"XXXII.

O que nos consola, entretanto, é que talvez nunca tenha ficado tão claro que essa "displicência" felizmente está com os dias contados, já que hoje é consenso que, dentre os importantes legados deixados a historiografia contemporânea, está trabalhar a compreensão do passado traumático e de seu processamento, como forma de disso retirar valiosas contribuições para nos afastar desse mesmo passado em direção a um futuro diferente.

\section{CONCLUSÃO OU O SILÊNCIO DOS (NÃO TÃO) INOCENTES}

As conquistas da historiografia que tem por objeto a escrita da história a partir do trauma foram muitas e muito significativas, sobretudo a partir do ano de 2011, quando surgiu a Lei 12.527, conhecida como Lei de acesso a informação pública. Não há dúvidas de que registramos ganhos no volume e qualidade das pesquisas produzidas, fato que reflete sobretudo no número de publicações, variedades de temas abordados e na construção de espaços acadêmicos e institucionais para essa perspectiva de escrita da história.

Apesar de ter passado por um momento de ampliação no que diz respeito a temas e abertura no que diz respeito à abordagens e enfoques, persiste, ainda, uma limitação cronológica responsável por, no Brasil, a escrita da história sob a perspectiva do trauma estar sempre e necessariamente ligada a ditadura militar.

Ao que vejo, isso se deve muito em razão da tão debatida e criticada Anistia. Porém, é errado pensar no silêncio e esquecimento como consequências diretas ou que vem única e exclusivamente em razão da Lei de Anistia, afinal também se nota a intenção de silêncio e esquecimento, adotada como uma forma de "apagar os rastros", em outros episódios traumáticos que não aquele dos anos de 1964 a 1985.

Entendo, desse modo, que é chegada a hora de rompermos as amarras que nos ligam apenas a esse recorte temporal, já que episódios traumáticos deixados pela ditadura - seja a do período militar ou outra, como a do Estado-Novo de Vargas -, bem como por outros eventos que igualmente usam de (mais ou menos) violência, ameaça e repressão, contra um ou mais grupos, no Brasil e fora dele, não podem e nem devem ficar silenciados e forçadamente esquecidos.

$\mathrm{O}$ esquecimento e silêncio dos (não tão) inocentes precisa, sem dúvidas, ser combatido, sendo duas as justificativas para tanto. Primeiro, por que é somente através do testemunho dos inocentes que a consciência coletiva pode ser construída e o trabalho de luto realizado. Seu silêncio, pelo contrário, favorece a melancolia, uma vez que o trauma não elaborado tende a se repetir. Assim, mesmo que se sabia que o silêncio se dá muitas vezes pela necessidade que tem a própria vítima - que traumatizada pela forma como foi tratada, recusa-se a travar qualquer diálogo a respeito do fato, abrindo-se, quando muito, significativo tempo depois, época em que seu psicológico, apesar de em tese recuperado, encarregou-se de propositadamente apagá-los, em parte -, esse 


\section{HISTÓRIA (DO TEMPO PRESENTE), MEMÓRIA E TRAUMA NA DITADURA DO ESTADO NOVO NO BRASIL (1937-1945) \\ WAGNER AUGUSTO HUNDERTMARCK POMPÉO}

testemunho, mesmo que ocorrido algum tempo depois, é, sim, importante, seja para a própria vítima, seja para a sociedade.

A outra, contudo, dá-se por uma perspectiva governamental, daquilo que podemos chamar de "o silêncio dos não tão inocentes", já que é sabido que o próprio Brasil, enquanto Estado soberano, durante muito tempo, fez questão que tais experiências não fossem trazidas a público, seja porque o desrespeito a seus cidadãos lhe gera consequências perante organismos internacionais do qual é signatário, seja porque também por isso é capaz de lhe gerar o dever de indenizar pecuniariamente às vítimas e seus familiares.

É somente quando lembrados e discutidos criticamente e de um modo mais amplo (temporal e espacialmente falando), como forma de disso retirarmos valiosas contribuições para nos afastar desse mesmo passado em direção a um futuro diferente, que não apenas melhor compreenderemos a relação havida entre história (do tempo presente), memória e trauma, como, sobretudo, de outras experiências igualmente necessárias ao alcance do que Maurice Halbwachs denominou como memória coletiva.

\section{Notas}

IBacharel em Direito, formado pela Faculdade Metodista de Santa Maria - FAMES, Instituição de Ensino Superior que compõe a Rede Metodista de Educação do Sul. Advogado, tem escritório na cidade de Santa Maria - RS, Porto Alegre - RS e Campo Grande - MS. Especialista em Ciências Penais, Pós-Graduado pelo Instituto de Direito RS, Rede de Ensino LFG e UNIDERP-ANHANGUERA. Formado Pedagogicamente pelo Programa Especial de Graduação para Formação de Professores para o Ensino Profissional e Tecnológico, no eixo de Direito, Gestão e Negócios, da Universidade Federal de Santa Maria - UFSM. É Pós-Graduado em Gestão Pública pela Universidade Federal de Santa Maria - UFSM. Mestre na área de concentração "Direitos Emergentes na Sociedade Global", com ênfase/linha de pesquisa afeta a "Direitos na Sociedade em Rede", da Universidade Federal de Santa Maria - UFSM. Doutorando em História pela Universidade Federal de Santa Maria - UFSM, na área de concentração "História, pode e cultura" e linha de pesquisa "Cultura, migrações e trabalho", na qual é orientado pela Profa. Dra. Gláucia Viera Ramos Konrad. Foi professor em Cursos Preparatórios para as Carreiras Jurídicas Públicas e, atualmente, é Professor nos cursos de Graduação e Pós-Graduação da Faculdade de Direito de Santa Maria - FADISMA. E-mail para contato: wagner@mmtadvogados.com.br.

${ }^{\text {II }}$ FAUSTO, Boris. A História do Brasil. São Paulo: Editora da Universidade de São Paulo, 2015, pág. 310-311.

III FAUSTO, Boris. A História do Brasil. São Paulo: Editora da Universidade de São Paulo, 2015, pág. 311.

IV CARVALHO, José Murilo de. Cidadania no Brasil: o longo caminho. 4ed. Rio de Janeiro: Civilização Brasileira, 2003, pág. 110-126.

V KONRAD, Gláucia Viera Ramos; KONRAD, Diorge Alceno. O Rio Grande do Sul e o Brasil na Historiografia do Trabalho (1930-1945). Revista Mundos do Trabalho. Vol. 5, n. 10, julho-dezembro de 2013, pág. 91-105.

VI KONRAD, Diorge Alceno. O fantasma do medo: o Rio Grande do Sul, a repressão policial e os movimentos sócio-políticos (1930-1937). Tese (Doutorado em História Social do Trabalho). Campinas: IFCH-Unicamp, 2004, pág. 141.

VII ALVES, Ronaldo Sávio Paes et al. Imagens e representações da violência oficial no Brasil: era Vargas e ditadura militar. In: SIMPÓSIO NACIONAL DE HISTÓRIA, 23., 2005, Londrina. Anais do XXIII Simpósio Nacional de História - História: guerra e paz. Londrina: ANPUH, 2005. CD-ROM, pág. 03.

VIII GOULART, Silvana. Sob a Verdade Oficial: Ideologia, propaganda e censura no Estado Novo. São Paulo. Marco Zero 1990, pag. 143.

IX KONRAD, Diorge Alceno. O fantasma do medo: o Rio Grande do Sul, a repressão policial e os movimentos sócio-políticos (1930-1937). Tese (Doutorado em História Social do Trabalho). Campinas: IFCH-Unicamp, 2004, pág. 143.

${ }^{X}$ MAGALHÃES, Fernanda Torres. O rosto e o caráter: fotografias no universo policial do DEOPS/SP. In. Revista Histórica. Ano 2, nº. 2. São Paulo: AESP, ago, 2000, pág. 51-52. 


\section{HISTÓRIA (DO TEMPO PRESENTE), MEMÓRIA E TRAUMA NA DITADURA DO ESTADO NOVO NO BRASIL (1937-1945) \\ WAGNER AUGUSTO HUNDERTMARCK POMPÉO}

XI FICO, Carlos. História do Tempo Presente, eventos traumáticos e documentos sensíveis: o caso brasileiro. Varia história. [online]. 2012, vol.28, n.47, pp.43-59. ISSN 0104-8775. http://dx.doi.org/10.1590/S0104-87752012000100003.

XII “(...) o presente é o nosso lugar de indagação e de análise. Os embates concernentes à luta pela memória configuram-se de maneira evidente em valores e referenciais que são também do presente. É a partir do presente que fazemos nossas indagações sobre nosso passado que é recente e inacabado, no sentido de que muitos aspectos e consequências do período militar ainda encontram-se entre nós (...)". SILVA, Walkiria Oliveira. Construções de memórias da Ditadura Militar brasileira: entre o trauma e o esquecimento. Cad. Pesq. Cdhis, Uberlândia, v.23, n.2, 2010, pág. 511.

${ }^{X I I I}$ A respeito de tais eventos, que vão muito além do Holocausto, quase sempre tratado com maior ênfase ou até mesmo exclusividade pela historiografia tradicional, interessante a crítica de Andreas Huyssen, quando destaca a necessidade de estarmos atentos ao que denominou "geografias alternativas doo modernismo", que "emergiram em nosso horizonte desde a ascensão dos estudos pós-coloniais e de uma nova atenção para com a genealogia da globalização cultural”. HUYSSEN, Andreas. Geografias do modernismo em um mundo globalizante. In: Culturas do passado - presente: modernismos, artes visuais, políticas da memória. Rio de Janeiro: Contraponto, 2014, pág. 19-38.

XIV No mesmo sentido, sugere-se a leitura de: HUYSSEN, Andreas. Usos tradicionais do discurso sobre o Holocausto e o colonialismo. In: Culturas do passado - presente: modernismos, artes visuais, políticas da memória. Rio de Janeiro: Contraponto, 2014, pág. 1177-194.

XV SILVA, Walkiria Oliveira. História do tempo presente e a experiência ditatorial no Brasil: uma análise a partir do trauma e do esquecimento. Revista Eletrônica Cadernos de História, ano 7 , n. ${ }^{\circ}$ 1, junho de 2012, pág. 52.

XVI FICO, Carlos. História do Tempo Presente, eventos traumáticos e documentos sensíveis: o caso brasileiro. Varia hist. [online]. 2012, vol.28, n.47, pp.43-59. ISSN 0104-8775. http://dx.doi.org/10.1590/S0104-87752012000100003, pág. 46.

XVII RÜSEN, Jorn. Como dar sentido ao passado: questões relevantes de meta-história. In: História da Historiografia. n², março de 2009, pág. 164.

XVIII WINTER, JAY. A geração da memória: reflexões sobre o "boom da memória" nos estudos contemporâneos de história. In: SELLIGMAN-SILVA, Márcio (Org.). Palavra e imagem: memória e escritura. Chapecó, SC: Argos, 2006, pág. 67-90.

XIX WINTER, JAY. A geração da memória: reflexões sobre o "boom da memória" nos estudos contemporâneos de história. In: SELLIGMAN-SILVA, Márcio (Org.). Palavra e imagem: memória e escritura. Chapecó, SC: Argos, 2006, pág. 67-90.

XX MEZAROBBA, Glenda. Um acerto de contas com o futuro - a Anistia e suas consequências: um estudo do caso brasileiro. São Paulo: Humanitas/Fapesp, 2006.

XXI HALBWACHS, Maurice. A Memória Coletiva. São Paulo: Centauro, 2006.

XXII HALBWACHS, Maurice. Fragmentos de la Memoria Coletctiva. Seleção e tradução. Miguel Angel Aguilar D. (texto em espanhol). Universidad Autónoma Meropolitana-Iztapalapa. Licenciatura em Psicologia Social. Publicado originalmente em Revista de Cultura Psicológica, Año 1, Número 1, México, UNAM-Faculdad de psicologia, 1991, pág. 02.

XXIII HALBWACHS, Maurice. A Memória Coletiva. São Paulo: Centauro, 2006, pág. 30.

XXIV HALBWACHS, Maurice. A Memória Coletiva. São Paulo: Centauro, 2006, pág. 39.

XXV HALBWACHS, Maurice. A Memória Coletiva. São Paulo: Centauro, 2006.

XXVI SELIGMANN, Márcio. Narrar o trauma - A questão dos testemunhos de catástrofes históricas. Psic. Clin. Rio de Janeiro, Vol. 20, nº. 1, 2008, pág. 69.

XXVII FREUD, Sigmund. "Luto e Melancolia". In: Obras psicológicas completas de Sigmund Freud: Edição Standard brasileira. Vol. XIV. Rio de Janeiro: Imago, 1996.

XXVIII FREUD, Sigmund. "Recordar, Repetir e Elaborar". In: Obras psicológicas completas de Sigmund Freud: Edição Standard brasileira. Vol. XII. Rio de Janeiro: Imago, 1996.

XXIX SILVA, Walkiria Oliveira. História do tempo presente e a experiência ditatorial no Brasil: uma análise a partir do trauma e do esquecimento. Revista Eletrônica Cadernos de História, ano 7, n. ${ }^{\circ}$ 1, junho de 2012, pág. 53.

XXX RICOEUR, Paul. A memória, a história, o esquecimento. Campinas: Editora Unicamp, 2007, pág. 8592.

XXXI LACAPRA, Dominick. Escribir la historia, Escribir el trauma. $1^{\mathrm{a}}$ ed. Buenos Aires: Nueva Vision, 2005 .

Cadernos do Tempo Presente, São Cristóvão-SE, v. 09, n. 02, p. 17-27, jul./dez. 2018

http://www.seer.ufs.br/index.php/tempo 


\section{HISTÓRIA (DO TEMPO PRESENTE), MEMÓRIA E TRAUMA NA DITADURA DO ESTADO \\ NOVO NO BRASIL (1937-1945) \\ WAGNER AUGUSTO HUNDERTMARCK POMPÉO}

XXXII KEHL, MARIA RITA. Tortura e sintoma social. In: TELES, Edson; SAFATLE, Vladimir. O que resta da ditadura. São Paulo: Boitempo, 2010, pág. 132.

\section{REFERÊNCIAS}

ALVES, Ronaldo Sávio Paes et al. Imagens e representações da violência oficial no Brasil: era Vargas e ditadura militar. In: SIMPÓSIO NACIONAL DE HISTÓRIA, 23., 2005, Londrina. Anais do XXIII Simpósio Nacional de História - História: guerra e paz. Londrina: ANPUH, 2005. CD-ROM.

CARVALHO, José Murilo de. Cidadania no Brasil: o longo caminho. 4ed. Rio de Janeiro: Civilização Brasileira, 2003.

FAUSTO, Boris. A História do Brasil. São Paulo: Editora da Universidade de São Paulo, 2015.

FICO, Carlos. História do Tempo Presente, eventos traumáticos e documentos sensíveis: o caso brasileiro. Varia história. [online]. 2012, vol.28, n.47, pp.43-59. ISSN 0104-8775. http://dx.doi.org/10.1590/S0104-87752012000100003.

FREUD, Sigmund. "Luto e Melancolia". In: Obras psicológicas completas de Sigmund Freud: Edição Standard brasileira. Vol. XIV. Rio de Janeiro: Imago, 1996.

FREUD, Sigmund. "Recordar, Repetir e Elaborar". In: Obras psicológicas completas de Sigmund Freud: Edição Standard brasileira. Vol. XII. Rio de Janeiro: Imago, 1996.

GOULART, Silvana. Sob a Verdade Oficial: Ideologia, propaganda e censura no Estado Novo. São Paulo. Marco Zero 1990.

HALBWACHS, Maurice. A Memória Coletiva. São Paulo: Centauro, 2006.

HUYSSEN, Andreas. Geografias do modernismo em um mundo globalizante. In: Culturas do passado - presente: modernismos, artes visuais, políticas da memória. Rio de Janeiro: Contraponto, 2014.

HUYSSEN, Andreas. Usos tradicionais do discurso sobre o Holocausto e o colonialismo. In: Culturas do passado - presente: modernismos, artes visuais, políticas da memória. Rio de Janeiro: Contraponto, 2014.

KEHL, MARIA RITA. Tortura e sintoma social. In: TELES, Edson; SAFATLE, Vladimir. O que resta da ditadura. São Paulo: Boitempo, 2010.

KONRAD, Diorge Alceno. O fantasma do medo: o Rio Grande do Sul, a repressão policial e os movimentos sócio-políticos (1930-1937). Tese (Doutorado em História Social do Trabalho). Campinas: IFCH-Unicamp, 2004. 


\section{HISTÓRIA (DO TEMPO PRESENTE), MEMÓRIA E TRAUMA NA DITADURA DO ESTADO \\ NOVO NO BRASIL (1937-1945) \\ WAGNER AUGUSTO HUNDERTMARCK POMPÉO}

KONRAD, Gláucia Viera Ramos; KONRAD, Diorge Alceno. O Rio Grande do Sul e o Brasil na Historiografia do Trabalho (1930-1945). Revista Mundos do Trabalho. Vol. 5, n. 10, julho-dezembro de 2013.

LACAPRA, Dominick. Escribir la historia, Escribir el trauma. $1^{\mathrm{a}}$ ed. Buenos Aires: Nueva Vision, 2005.

MAGALHÃES, Fernanda Torres. O rosto e o caráter: fotografias no universo policial do DEOPS/SP. In. Revista Histórica. Ano 2, nº 2. São Paulo: AESP, ago, 2000.

MEZAROBBA, Glenda. Um acerto de contas com o futuro - a Anistia e suas consequências: um estudo do caso brasileiro. São Paulo: Humanitas/Fapesp, 2006.

RICOEUR, Paul. A memória, a história, o esquecimento. Campinas: Editora Unicamp, 2007.

RÜSEN, Jorn. Como dar sentido ao passado: questões relevantes de meta-história. In: História da Historiografia. n² 2 , março de 2009.

SELIGMANN, Márcio. Narrar o trauma - A questão dos testemunhos de catástrofes históricas. Psic. Clin. Rio de Janeiro, Vol. 20, nº. 1, 2008.

SILVA, Walkiria Oliveira. Construções de memórias da Ditadura Militar brasileira: entre o trauma e o esquecimento. Cad. Pesq. Cdhis, Uberlândia, v.23, n.2, 2010.

SILVA, Walkiria Oliveira. História do tempo presente e a experiência ditatorial no Brasil: uma análise a partir do trauma e do esquecimento. Revista Eletrônica Cadernos de História, ano 7, n. ${ }^{\circ}$, junho de 2012.

WINTER, JAY. A geração da memória: reflexões sobre o "boom da memória" nos estudos contemporâneos de história. In: SELLIGMAN-SILVA, Márcio (Org.). Palavra e imagem: memória e escritura. Chapecó, SC: Argos, 2006, pág. 67-90. 